"Marie" and "Dean," Two Cases with Different Alliance Trajectories \& Outcomes

L.A. Burckell \& S. McMain

Pragmatic Case Studies in Psychotherapy, http://pcsp.libraries.rutgers.edu

Volume 7, Module 2, Article 2, pp. 246-267, 06-05-11 [copyright by authors]

\title{
Contrasting Clients in Dialectical Behavior Therapy for Borderline Personality Disorder: “Marie” and “Dean,” Two Cases with Different Alliance Trajectories \& Outcomes
}

\author{
LISA A. BURCKELL ${ }^{\mathrm{a}, \mathrm{c}}$ \& SHELLEY MCMAIN ${ }^{\mathrm{b}}$ \\ a St. Joseph's Healthcare, Hamilton, Ontario, and Department of Psychiatry and Behavioural Neurosciences, \\ McMaster University \\ ${ }^{\mathrm{b}}$ Borderline Personality Disorder Clinic, Department of Psychiatry, University of Toronto \\ ${ }^{\mathrm{c}}$ Correspondence concerning this article should be addressed to Lisa A. Burckell, St. Joseph's Healthcare, Hamilton, \\ Ont., L8N 4A6, and Department of Psychiatry and Behavioural Neurosciences, McMaster University, Canada. \\ Email: lburckel@stjosham.on.ca
}

\begin{abstract}
Dialectical Behavior Therapy (DBT; Linehan, 1993a) has garnered a strong evidence base to support its efficacy in treating borderline personality disorder (BPD). Despite this, some clients do not benefit from evidenced-based approaches. There is a recent emphasis on identifying the processes and mechanisms of DBT in order to improve treatment outcomes. This report describes the course of treatment for two individuals who were treated with one-year of standard, outpatient DBT in the context of a randomized control trial. The two clients were selected because (1) both reported poor initial alliances, and (2) they had different outcomes. The first case, "Marie," showed considerable change across a broad range of outcomes whereas the second case, "Dean," made only limited treatment gains. The two cases are contrasted in order to highlight potential factors that may have contributed to the different alliance trajectories and outcomes. We explore several hypotheses to help to explain the relationship between treatment outcome and client characteristics, the therapeutic alliance, the consultation team, and the research context.
\end{abstract}

Key words: borderline personality disorder; Dialectical Behavior Therapy (DBT); therapeutic alliance; suicidal behavior; case studies; clinical case studies; comparative case studies

\section{CASE CONTEXT AND METHOD}

\section{Treating Borderline Personality Disorder with Dialectical Behavior Therapy}

Individuals with borderline personality disorder (BPD) are considered to be difficult to treat (e.g., Aviram, Brodsky, Stanley, 2006). Treatment challenges stem from the complexity of the problems that these individuals experience (e.g., suicidal and behaviors) and the difficulties of establishing a strong therapeutic alliance. The severity of their problems leads individuals with BPD to seek treatment at high rates (e.g., Bender, Dolan, Skodol, Sanislow, Dyck, \& McGlashan, 2001; Zanarini, Frankenburg, Hennen, \& Silk, 2004). Furthermore, treatment 
"Marie" and "Dean," Two Cases with Different Alliance Trajectories \& Outcomes

L.A. Burckell \& S. McMain

Pragmatic Case Studies in Psychotherapy, http://pcsp.libraries.rutgers.edu

Volume 7, Module 2, Article 2, pp. 246-267, 06-05-11 [copyright by authors]

failures and dropouts are common (e.g., Skodol, Buckley, \& Charles, 1983). In response to these challenges, research has focused on developing interventions to treat BPD. Among these, Dialectical Behavior Therapy (DBT; Linehan, 1993), has received the most empirical attention to date.

DBT is a broad-based cognitive behavioral approach. Grounded in dialectical philosophy, DBT balances change strategies drawn from cognitive behavioral principles with acceptancebased strategies rooted in Zen traditions. Research on DBT has shown it to be effective in reducing suicidal and non-suicidal self-injurious behaviors, health care utilization (e.g. emergency room visits, inpatient days) and treatment dropout (e.g., Linehan et al., 2006). While DBT has been shown to be effective across a broad range of clinical outcomes relevant to the disorder, like other empirically supported treatments, DBT is not successful with all patients. Approximately 36\% of individuals diagnosed with BPD fail to respond to DBT (Salsman, Harned, Secrist, Comtois, \& Linehan 2008). Thus, there is a need to improve upon existing treatments. Identifying factors that predict successful outcomes is one way of learning how to enhance treatment.

\section{A Focus on the Therapeutic Alliance}

Among the various factors that could be related to outcome, the therapeutic alliance and its relationship to outcome is a prime candidate for investigation. The therapeutic alliance is construed as the affective bond, and the agreement on therapeutic tasks and goals between the client and therapist (Bordin, 1979). Numerous studies support a positive relationship between the therapeutic alliance and treatment outcomes (Barber, Connolly, Crits-Christoph, Gladis, \& Siqueland, 2000; Klein, Schwartz, Santiago, Vivian, Vocisano, Castonguay, et al., 2003; Zuroff \& Blatt, 2007). Furthermore, the alliance has been found to mediate the relationship between outcome and various therapeutic processes, including client therapy expectations (Meyer et al., 2002), clients' interpersonal style (Hardy et al., 2001), and affect regulation during the initial phase of posttraumatic stress disorder treatment (Cloitre, Stovall-McClough, Miranda, \& Chemtob, 2004).

Undoubtedly the therapeutic alliance plays a particularly important role in the treatment of BPD. Individuals with BPD features experience significant interpersonal problems (American Psychiatric Association, 2000; Daley et al., 2000) and these issues frequently impact the treatment relationship. Psychoanalytic therapists have long recognized the importance of the alliance in treating individuals with BPD (e.g., Horowitz, Gabbard, Allen, Frieswyk, Colson, Newsome, et al., 1996). Similarly, Linehan developed DBT with a clear appreciation of the challenges of building and maintaining a therapeutic relationship with individuals diagnosed with BPD (Linehan,1993a). Linehan understood that treatment for BPD would not succeed unless it incorporated strategies to increase treatment retention and engagement and, procedures for motivating therapists.

Linehan's view of the alliance in DBT influences the treatment philosophy and the treatment strategies themselves. First, the alliance in DBT is built on respect for client as an individual and a belief in the client's ability to change. Second, the alliance is based on a real 
"Marie" and "Dean," Two Cases with Different Alliance Trajectories \& Outcomes

L.A. Burckell \& S. McMain

Pragmatic Case Studies in Psychotherapy, http://pcsp.libraries.rutgers.edu

Volume 7, Module 2, Article 2, pp. 246-267, 06-05-11 [copyright by authors]

relationship in which clients and therapists participate equally and influence each other (Swales \& Heard, 2007). Third, the alliance is considered to be both the vehicle of change, and the context in which change occurs. In Linehan's words: "The relationship in DBT has a dual role. The relationship is the vehicle through which the therapist can effect therapy; it is also the therapy" (1993a, p. 514). Ultimately, a strong alliance in DBT, as in other treatments, is based on a relationship characterized by respect and trust, and a clear understanding of and agreement on therapeutic goals and methods. DBT has explicit strategies developed to enhance these aspects of the alliance. For example, behaviors that compromise the relationship, either by the client or the therapist, are an explicit focus of treatment.

The present paper examines the role of the therapy alliance in the DBT treatment of BPD. Our specific interest is in the development of the therapy alliance and factors associated with positive alliances over the course of treatment. To achieve these aims we present two case examples, Marie and Dean. The clients differed in terms of their alliance trajectories and outcomes. Specifically, while both clients reported poor initial alliances, at the end of treatment Marie had developed a strong alliance with her therapist and showed significant gains across all outcomes. In contrast, Dean reported low alliance ratings over the course of treatment and exhibited limited treatment gains. The two cases are contrasted to highlight potential factors that may have contributed to differences in alliance trajectories and outcome.

\section{Treatment Context}

Marie and Dean received DBT at an outpatient clinic specializing in the treatment of BPD. Marie and Dean were in the DBT condition of a randomized clinical trial comparing DBT and "general psychiatric management, including a combination of psychodynamically informed therapy and symptom-targeted medication management derived from specific recommendations in APA guidelines for borderline personality disorder" (McMain, Links, Gnam, et al., 2009, p. 1365). The DBT condition involved one year of standard outpatient DBT. One of the primary goals of this RCT was to determine the efficacy of DBT relative to a robust comparator treatment in a large scale replication trial conducted independent of the treatment developer. Thus, Marie and Dean were treated in a setting that is typical of a "real world" clinical setting.

As further context to the cases of Marie and Dean, the findings of the randomized trial have been summarized by the authors as follows:

Results: Both groups [DBT and General Psychiatric Management] showed improvement on the majority of clinical outcome measures after 1 year of treatment, including significant reductions in the frequency and severity of suicidal and nonsuicidal self-injurious episodes and significant improvements in most secondary clinical outcomes. Both groups had a reduction in general health care utilization, including emergency visits and psychiatric hospital days, as well as significant improvements in borderline personality disorder symptoms, symptom distress, depression, anger, and interpersonal functioning. No significant differences across any outcomes were found between groups. Conclusions: These results suggest that individuals with borderline personality disorder benefited equally from dialectical behavior therapy and a well-specified treatment delivered by psychiatrists with expertise in the treatment of borderline personality disorder (McMain, Links, \& Gnam, 2009). 
"Marie" and "Dean," Two Cases with Different Alliance Trajectories \& Outcomes

L.A. Burckell \& S. McMain

Pragmatic Case Studies in Psychotherapy, http://pcsp.libraries.rutgers.edu

Volume 7, Module 2, Article 2, pp. 246-267, 06-05-11 [copyright by authors]

A more detailed description of the study and its findings ca be found in McMain, Links, Gnam, et al., 2009).

\section{Confidentiality}

Both clients’ identities were disguised to protect their confidentiality.

\section{Assessment Measures in the Randomized Clinical Trial}

\section{$\underline{\text { Diagnostic Assessment }}$}

Marie and Dean, as the other participants in the randomized trial, were initially assessed to determine whether they met the following study inclusion criteria: (1) a Diagnostic and Statistical Manual for DSM-IV (DSM-IV; American Psychiatric Association, 2000) diagnosis of BPD; and (2) at least two suicidal or non-suicidal self-injurious behaviors within the past 5 years with at least one of these behaviors occurring in last 3 months. The exclusion criteria included (1) the onset of a psychotic disorder prior to age 17; (2) a diagnosis of bipolar I disorder; (3) current active substance dependence in the past 30 days; (4) organic brain syndrome or mental retardation; or (5) chronic or serious physical health problem.

Assessors used the following measures to determine DSM-IV diagnoses: the Structured Clinical Interview I for the DSM-IV to assess Axis I Disorders (SCID-I; First et al., 1995) and the International Personality Disorder Exam (IPDE; Loranger, 1995) to assess all Axis II disorders.

Primary and Secondary Symptom Assessment at Baseline, During Therapy, and at Follow Up

Participants in the randomized were assessed at baseline (i.e., initial assessment prior to start of treatment) and every four months during the active one year treatment phase, and at every six months during the two-year follow-up period on both primary and secondary outcome measures. In the present case studies, we only present the data through the 18-month follow up, since Dean did not attend the 2-year follow up assessment.

The primary outcome measures included the following:

- Number of Suicidal and Self-Injurious Behaviors

- Number of Emergency Room Visits Due to Suicidal Behavior

- Number of Psychiatric Floor Admissions

- Number of Psychiatric Floor Days 
"Marie" and "Dean," Two Cases with Different Alliance Trajectories \& Outcomes

L.A. Burckell \& S. McMain

Pragmatic Case Studies in Psychotherapy, http://pcsp.libraries.rutgers.edu

Volume 7, Module 2, Article 2, pp. 246-267, 06-05-11 [copyright by authors]

The secondary outcome measures included the following:

- The Beck Depression Inventory (BDI; Beck, Steer, \& Brown, 1996), to measure depressive symptoms.

- The State-Trait Anger Expression Inventory (STAXI; Spielberger, 1988), to assess anger expression.

- $\quad$ The Symptom Checklist-90 (SCL-90; Derogatis, 1993), to measure general distress.

- $\quad$ The Inventory of Interpersonal Problems (IIP; Horowitz, Rosenberg, Baer, Ureño, \& Villaseñor, 1988), to assess interpersonal problems.

- The Zanarini Rating Scale for Borderline Personality Disorder (ZAN-BPD; Zanarini, Vujanovic, Parachini, Boulanger, et al., 2003), to identify change in borderline symptoms.

\section{$\underline{\text { Process Measure }}$}

The Working Alliance Inventory (WAI; Tracey \& Kokotovic, 1989) was used to assess the quality of the therapeutic relationship. Higher alliance scores are associated with stronger alliances and better outcomes (e.g., Martin, Garske, \& Davis, 2000). The WAI was administered to both the clients and therapists following sessions 1 through 4 (Baseline), and at the month 4, 8, and 12 assessments.

\section{Treatment}

Treatment involved one-year of outpatient DBT based on Linehan (1993a,b). Treatment consisted of the standard four modes of DBT, including: one-hour of weekly individual therapy, 2 hours of weekly skills group, 24/7 telephone consultation, and a two-hour weekly consultation meeting for therapists which focused on enhancing therapists' motivation and adherence to DBT. Clients were informed that if they missed 4 consecutive individual or group sessions, they would be considered a drop out from treatment.

\section{Diary Card Monitoring}

Therapists monitored progress on a weekly basis through client diary cards. Clients daily rated their urges, thoughts, feelings, and actions, such as urges to suicide, to self-injure, and to quit therapy. Additionally, diary cards were used by clients to record their skill practice and the effectiveness of skills. At the beginning of each individual therapy session, the therapist and client reviewed the diary card to develop the session agenda and to provide feedback about treatment in an on-going basis. 
"Marie" and "Dean," Two Cases with Different Alliance Trajectories \& Outcomes

L.A. Burckell \& S. McMain

Pragmatic Case Studies in Psychotherapy, http://pcsp. libraries.rutgers.edu

Volume 7, Module 2, Article 2, pp. 246-267, 06-05-11 [copyright by authors]

\section{THE CLIENTS}

\section{Marie - Good Alliance and Outcome}

Marie was a 42 year-old, single woman who was unemployed and living in a boarding home at the start of treatment. She reported limited family contact and no friends, and had an extensive history of suicide attempts, aggression, and alcohol abuse.

\section{Dean - Poor Alliance and Outcome}

Dean was a 25 year-old, clinically obese man who had recently graduated from college with a degree in music. Because of college debts, he was living with his parents. He had a long history of mental health problems. Dean reported problems with anger, assault, isolation and alienation, and interpersonal relationships.

\section{GUIDING CONCEPTION}

Case conceptualization in DBT is influenced by a biosocial model, learning theory, Zen, and dialectical philosophy (Koerner \& Linehan, 2006). DBT treatment is highly structured and organized by stages, which include a pretreatment phase, also called a "pretreatment" or "orientation" phase, and four subsequent stages corresponding to patient severity (Linehan 1993). During the precommitment phase, the task of the therapist is to clarify client goals, assess behaviors, provide education about BPD, DBT, and other relevant disorders, and secure an explicit commitment from the client to engage in treatment.

In Stage 1 of the treatment stage, the primary goal is to help clients reduce behavioral dyscontrol and increase stability and safety. DBT has been primarily developed and evaluated for clients in Stage 1. The specific targets in Stage 1 include: 1) eliminating suicidal and selfinjurious behaviors, 2) decreasing therapist and client behaviors that interfere with treatment, 3) reducing quality of life interfering behaviors (e.g., mental health, vocational, and interpersonal), and 4) increasing behavioral skills. Once behavioral stability is achieved, clients may progress to a Stage 2-focused treatment that targets enhancing emotional experiencing of trauma-related issues. In Stage 3, treatment goals include enhancing self-respect, interpersonal relatedness, and functioning. In the final stage, Stage 4, treatment focuses on increasing the individual's capacity for joy and meaning.

DBT’s biosocial model (Linehan, 1993a; Crowell, Beauchaine, \& Linehan, 2009) informs the development of BPD. The model explains that individuals with BPD are born with an emotional vulnerability. In response to emotional stimuli, these individuals respond quickly, experience intense reactions, and have difficulty returning to their baseline. People often invalidate these emotionally vulnerable individuals by failing to recognize their emotional sensitivity and by failing to respond to them with support. Instead, others respond with invalidation, which leads these individuals to develop increased vulnerability to emotional stimuli. Linehan (1993a) contends that over time this repeated pattern of emotional sensitivity that is met with invalidation leads to the development of the pervasive emotion regulation 
"Marie" and "Dean," Two Cases with Different Alliance Trajectories \& Outcomes

L.A. Burckell \& S. McMain

Pragmatic Case Studies in Psychotherapy, http://pcsp.libraries.rutgers.edu

Volume 7, Module 2, Article 2, pp. 246-267, 06-05-11 [copyright by authors]

difficulties underlying BPD. Ultimately, individuals with BPD engage in various dysfunctional behaviors (e.g., self injury, binging, and substance abuse) to manage uncontrollable negative emotions, since they lack more skillful ways to regulate emotion.

The implications of this theory for treatment are that the primary goal of treatment is to help individuals learn strategies to modulate their emotions through the acquisition of effective coping strategies. Consequently, DBT treatment strategies target mechanisms associated with emotion regulation. The specific strategies utilized in DBT are derived from learning theory, Zen, and dialectical theory. Learning theory informs the development and maintenance of behavior and articulates methods for promoting behavioral change. DBT therapists utilize behavioral analyses to identify the stimuli controlling specific behaviors. Behavioral analyses can point to skills deficits, problematic emotions, dysfunctional cognitions, and problematic contingencies that maintain dysfunctional behaviors and interfere with the development of effective behavior (Koerner \& Linehan, 1996).

In addition to an emphasis on change, emotional and behavioral regulation are also fostered by helping individuals to acknowledge and accept their emotions. Acceptance-based strategies in DBT are rooted in Zen philosophy, and include validation strategies and mindfulness skills. Awareness of emotions is a prerequisite to the development of emotional and behavioral regulation. People need to be aware of their experience in order to gain control over their responses to specific emotions. Clients learn mindfulness techniques, including observing and describing non-judgmentally, to help them increase acceptance of current experiences. DBT therapists balance a focus on change with validation strategies, which entail communicating the kernel of wisdom in the individual's response. Ultimately, validation promotes self-validation of feelings, behaviors, and thoughts (Linehan, 1993a, 1997).

Dialectical philosophy provides an overarching framework in treatment. According to dialectical philosophy, the synthesis of opposite perspectives facilitates change (Linehan, 1993a). Dialectical philosophy also emphasizes viewing issues holistically by understanding how parts cannot be understood in isolation. The central dialectical strategy in DBT involves the reconciliation of change and acceptance. Dialectical strategies also include helping clients increase dialectical thinking by seeking what is missing from their perspective, acknowledging the missing part, and synthesizing it. Linehan (1993a) identifies “dialectical dilemmas” or behavioral patterns that characterize individuals with BPD. Therapists use these patterns to explain how clients are "stuck" engaging in dysfunctional behaviors. Moreover, therapists work to reconcile these opposing patterns to promote change. In DBT, there is also an emphasis on understanding how the context and the individual transact. Specifically, therapists identify how clients affect their environments and how their environments, including the therapist and the treatment, affect the client. 
"Marie" and "Dean," Two Cases with Different Alliance Trajectories \& Outcomes

L.A. Burckell \& S. McMain

Pragmatic Case Studies in Psychotherapy, http://pcsp. libraries.rutgers.edu

Volume 7, Module 2, Article 2, pp. 246-267, 06-05-11 [copyright by authors]

\section{ASSESSMENT}

\section{Assessment of Marie}

Marie was a 42-year-old single woman who was unemployed and living in a boarding home at the start of treatment. Marie reported that she had limited contact with her family; she had no friends. Marie described difficulties trusting others and fearing rejection. Furthermore, Marie had an extensive history of suicide attempts and alcohol abuse. Marie became aggressive when she was drinking which lead to several negative consequences; she was both a victim and a perpetrator of physical assault. Marie had several arrests for physical assault that all occurred when she had been drinking.

Marie reported that she started to engage in suicidal behaviors at age 40. Of the 22 episodes that occurred over her lifetime, 19 occurred within the current year. Marie used methods that included overdosing, attempted hanging, cutting, smothering, and an attempted shooting. Additionally, the majority of these attempts were made with a lethal intent and resulted in numerous emergency room visits. And on one occasion, an attempt resulted in her hospitalization. Marie had also received substance abuse treatment to target her alcohol abuse. Based on the assessment, she met DSM-IV (APA, 2000) criteria for major depressive disorder, alcohol abuse, and BPD; she met 6 of 9 the diagnostic criteria. Marie's overall functioning received a GAF rating of 42, reflecting the presence of serious symptoms or any serious impairment in social, vocational, or educational functioning (American Psychiatric Association, 2000).

\section{Assessment of Dean}

Dean was a 25 year-old clinically obese man who had recently graduated from college with a degree in music. Dean had accumulated extensive debt due to student loans. As a result of his financial burden, he moved home with his parents. He had a lengthy history of mental health problems that escalated in his late teens following a break-up of a romantic relationship. At that time, he began to isolate himself and to avoid "everything." Ultimately, he withdrew to his bedroom for several months. Dean detailed problems with anger (e.g., tantrums, throwing objects, and assault), isolation and alienation, and interpersonal relationships.

Dean had an extensive history of non-suicidal, self-injurious behavior that started at age 20. Dean reported a lifetime history of approximately 360 episodes of non-suicidal self-injurious behaviors; 105 of these occurred in the past year. In contrast to Marie, Dean denies any history of suicide attempts. Dean's typical self-injurious behaviors included cutting, burning, strangulation, and head banging. Dean had a lengthy inpatient stay in the year preceding DBT treatment. Based on the assessment, he met DSM-IV criteria (American Psychiatric Association, 2000) for major depressive disorder, social phobia, BPD — he met 9 of the 9 diagnostic criteriaand narcissistic personality disorder. In addition, Dean was diagnosed with antisocial personality disorder features. Dean's overall functioning received a GAF rating of 45, indicating the presence of serious symptoms or any serious impairment in social, vocational, or educational functioning (APA, 2000). 
"Marie" and "Dean," Two Cases with Different Alliance Trajectories \& Outcomes

L.A. Burckell \& S. McMain

Pragmatic Case Studies in Psychotherapy, http://pcsp.libraries.rutgers.edu

Volume 7, Module 2, Article 2, pp. 246-267, 06-05-11 [copyright by authors]

\section{FORMULATION AND TREATMENT PLAN}

\section{Marie: Case Conceptualization}

Marie's significant life-threatening behaviors and mental health and interpersonal problems are characteristic of individuals in Stage 1 of DBT. A number of aspects of Marie's history can be understood within the context of the biosocial model. First, Marie' was described by her family as an emotional child who was "overly” sensitive. Marie's emotional sensitivity was in marked contrasted to her siblings. Marie described a childhood characterized by feelings of isolation and rejection by her family. In response to her family's critical remarks about her sensitivity, she reported feeling shame about her emotional experiences. She developed a belief that something was fundamentally wrong with her because she was more sensitive than others and less able to control her reactions. As a result, she attempted to conceal her emotions. Over time, Marie became hypervigilant to signs of rejection, which in turn, further heightened her sensitivity. Marie withdrew from her family and others in order to avoid their rejection, which in turn intensified her pain and sense of isolation.

Marie’s therapist viewed Marie's alcohol use, suicidal behaviors, and anger developed as a means to regulate negative emotions including anxiety and shame. Marie's anxiety and shame decreased immediately after engaging in these problematic behaviors, and therefore served to reinforce the behaviors. Thus, Marie needed to learn more effective coping strategies to regulate her emotions (i.e., behaviors without negative consequences). Marie's therapist also recognized that in order for Marie to change, Marie had to escape from the pattern of cycling between intense emotional vulnerability and self-invalidation. She and Marie strove to reconcile this dialectical dilemma by teaching Marie how to validate herself and to use skills to cope with intense feelings.

\section{Dean: Case Conceptualization}

Dean was also a Stage 1 client due to his recent suicidal and non-suicidal self-injurious behaviors, and severe mental health and interpersonal problems. His psychosocial history was consistent with the biosocial theory. Dean's family history of mental pointed some evidence of a genetic predisposition to emotion vulnerability. This may explain why Dean was described as overly sensitive. As a child, he was diagnosed with Attention Deficit/Hyperactivity Disorder. Dean's emotional vulnerability was in stark contrast to his family. Dean described his family as emotionally over-controlled. For example, his mother reportedly criticized him with a smile to mask her feelings. Although Dean tried to hide his feelings, his feelings were intense and difficult to conceal. When he expressed his emotions, he was criticized, and this generated feelings of shame about his emotions. As a result, Dean tried to avoid his emotional experience, which contributed to his inability to recognize or label his emotions. Because he lacked effective strategies to cope with his feelings, Dean used self-injury and anger to regulate his intense negative emotions.

Dean's therapist conceptualized that his problems developed from a fear of experiencing shame and primary anger. Dean's rage was viewed as a secondary response that protected him 
"Marie" and "Dean," Two Cases with Different Alliance Trajectories \& Outcomes

L.A. Burckell \& S. McMain

Pragmatic Case Studies in Psychotherapy, http://pcsp.libraries.rutgers.edu

Volume 7, Module 2, Article 2, pp. 246-267, 06-05-11 [copyright by authors]

from underlying feelings of vulnerability. Expressions of anger were frequently reinforced by others who avoided him or withdrew any critical feedback. Dean avoided primary emotional experiences, such as shame, and consequently he exhibited deficits in identifying his emotions. Dean's treatment focused on teaching him how to identify, accept, and experience his emotions, especially shame. Finally, Dean's therapist identified several dialectical dilemmas (Linehan, 1993) that threatened treatment, including vacillating between intense emotional expressions and discounting or inhibiting his emotions.

\section{6-8. COURSE OF TREATMENT, THERAPY MONITORING, AND CONCLUDING EVALUATION OF THE THERAPY'S PROCESS AND OUTCOME}

Discussion of the final three aspects of the therapy of Marie and Dean-the course of treatment, how the therapy was monitored through supervision groups, and the process and outcome of each-will be presented in a manner that interweaves these different therapy components. Specifically, the clients' outcomes will first be described, and then the reasons for their different outcomes will be explored in terms of (a) differences in client factors, (b) differences in therapist alliances, and (d) how the therapies were monitored by supervision groups that are a formal part of the DBT team's treatment model.

\section{Concluding Evaluation of Therapy Process and Outcome}

\section{Marie's Therapy}

Table 1 presents the primary and secondary outcomes for Marie and Dean.

Marie's Primary Outcome Measures. At the end of treatment (12 Months), Marie evidenced substantial improvement on all of the primary treatment outcomes. Specifically, she eliminated suicidal and self-injurious behaviors, emergency room visits due to suicidal behaviors, and psychiatric hospitalizations. Marie maintained her gains on these outcome domains over the course of one-year post treatment. However, by 18 months after treatment ended, Marie's behavior deteriorated. The re-emergence of problems coinciding with a relapse to alcohol abuse.

Marie's Secondary Outcome Measures. The secondary treatment outcomes included measures assessing depressive symptoms (BDI), general distress (SCL-90), anger (STAXI expressed anger), interpersonal problems (IIP), and BPD symptoms (ZAN-BPD). As shown in Table 1, at the end of treatment and at 1 year after treatment termination, Marie continued to show substantial improvements in her level of general symptom distress (SCL-90) and her BPD symptoms (ZAN-BPD) scores. Her scores on other outcomes measures showed variability with some positive and positive or negative change. By18 months after treatment ended, Marie showed increased dysfunction in the areas of anger, general symptom distress, interpersonal problems, and BPD symptoms. 
"Marie" and "Dean," Two Cases with Different Alliance Trajectories \& Outcomes

L.A. Burckell \& S. McMain

Pragmatic Case Studies in Psychotherapy, http://pcsp.libraries.rutgers.edu

Volume 7, Module 2, Article 2, pp. 246-267, 06-05-11 [copyright by authors]

Marie's Process Outcome - WAI. Figure 1 displays Marie’s WAI scores. Marie's alliance scores taken from the first four sessions reflected the presence of significant problems in the therapeutic relationship; Marie's alliance ratings were in the lowest $25^{\text {th }}$ percentile of all study participants at the beginning of treatment. Although Marie reported a poor initial alliance, her ratings diverged as treatment progressed. Specifically, over the course of treatment, Marie's ratings of the alliance increased to reflect a positive alliance trajectory-increased agreement on goals and tasks, and enhanced trust and respect. Although Marie's therapist's ratings were slightly higher than Marie's ratings at each time point, their alliance ratings followed a similar slope, suggesting that they shared a common perspective of their relationship as it evolved over the course of treatment.

Conclusion. Marie reported a strong therapeutic alliance in therapy. She evidenced significant improvement on all primary outcome measures over the course of treatment and throughout the year following treatment termination. However, she relapsed to alcohol abuse at 18 months post treatment termination and showed an overall deterioration in her behavior.

\section{Dean's Therapy}

Dean's Primary Outcome Measures. At the conclusion of treatment (Treatment - 12 months), Dean evidenced substantial improvement on the reduction of suicidal and self-injurious behaviors. Furthermore, Dean did not access ER or inpatient services for psychiatric reasons during his year of treatment. However, Dean's self-injurious behaviors re-emerged at the 6- and 12-month follow ups and he accessed the ER for psychiatric reasons once during the 12-month follow-up.

Dean's Secondary Outcome Measures. The secondary treatment outcomes included measures assessing depressive symptoms (i.e., BDI), general distress (i.e., SCL-90), anger (i.e., STAXI Anger Out), interpersonal problems (i.e., IIP), and BPD symptoms (i.e., ZAN-BPD). At the end of treatment, Marie evidenced significant worsening on all secondary measures except for BPD symptoms. By the 18-month follow up, Dean's scores mirrored his baseline scores.

At the end of therapy at 12 months, Dean's scores showed dramatic worsening, from 27 at baseline to 59 on depression; from 13 to 22 on anger; from .13 to 2.71 on general distress; and from 57 to 146 on interpersonal problems. On the other hand, his BPD symptoms had decreased, from 15 to 3. At 18-month follow-up, his depression and anger scores came down to his baseline levels, while his general distress and interpersonal problems continued to be elevated relative to his baseline. His BPD symptoms did remain improved relative to his baseline.

Dean Process Outcome - WAI. Figure 2 displays Dean's WAI scores. Similar to Marie, Dean's initial alliance ratings were in the lowest $25^{\text {th }}$ percentile at the beginning of treatment. However, Dean's alliance ratings remained low throughout treatment; at 4, 8, and 12 months, Dean's ratings never rose above a 3, indicating that on average he only occasionally felt that he and his therapist agreed on goals and that his therapist liked him. In contrast, Dean's therapist rated the alliance somewhat higher at all points, including at the first and last sessions. The 
"Marie" and "Dean," Two Cases with Different Alliance Trajectories \& Outcomes

L.A. Burckell \& S. McMain

Pragmatic Case Studies in Psychotherapy, http://pcsp.libraries.rutgers.edu

Volume 7, Module 2, Article 2, pp. 246-267, 06-05-11 [copyright by authors]

divergent rating patterns for Dean and his therapist may reflect an absence of a shared perception of the relationship or the purpose of therapy.

Conclusion. Dean's perception of the therapeutic alliance during the therapy was low. Although Dean eliminated all self-injurious behaviors during treatment, Dean evidenced significant worsening on the secondary outcome measures at the end of the treatment year except for borderline symptoms. Furthermore, relative to baseline, Dean evidenced substantial deterioration on the primary outcome measures at the 6-month and 12-month follow-ups, and on two of the secondary outcome measures (general distress and interpersonal problems) at 18month follow-up.

\section{Comparing and Contrasting Factors Influencing the Different Alliances and Outcomes}

We examine several factors that may have contributed to different outcomes in the case of Marie and Dean, including client factors, and interpersonal factors.

\section{$\underline{\text { Client Factors }}$}

Client factors may have contributed to different treatment outcomes. Marie and Dean shared a number of characteristics, including problems with under-regulated anger, low trust, social isolation, childhood neglect, shame around emotional expression, and suicidal behaviors. Despite these similarities, there were notable differences.

Age and Developmental Level. First, age and developmental level may have played a role in treatment. Marie was significantly older than Dean. Although age may have been a factor in this case, age has not been found to predict outcome in DBT treatment (Salsman et al., 2008). Instead, it may be that factors associated with age, including motivation, influenced outcome more than age per se.

Level of Motivation. There is considerable evidence that links low motivation to poor outcome (e.g., Norcross, Krebs, \& Prochaska, 2011). Many clients diagnosed with BPD enter treatment ambivalent about treatment and change. Because motivation is such a problem for individuals with BPD, the treatment was designed to address problems of motivation; the individual therapist role includes enhancing the client's motivation (Linehan, 1993a). When Marie started DBT, she had been struggling with her problems for many years. She acknowledged that she wanted to change and voiced regret about life passing her by. In contrast, Dean reported significant ambivalence about addressing his issues. Scheduling an initial treatment session with Dean was challenging and it took several weeks and numerous phone calls before his therapist was able to get him to agree to come in for a session. It is likely that Marie was more motivated to engage in treatment and this could have been due to the longstanding nature of her problems. In contrast, it is possible that because Dean had not lived with his problems long enough to feel truly distressed about them, he was less motivated to make changes. Thus, this contextual factor may have influenced their different degree of motivation and engagement. 
"Marie" and "Dean," Two Cases with Different Alliance Trajectories \& Outcomes

L.A. Burckell \& S. McMain

Pragmatic Case Studies in Psychotherapy, http://pcsp.libraries.rutgers.edu

Volume 7, Module 2, Article 2, pp. 246-267, 06-05-11 [copyright by authors]

Axis II Comorbidity. The presence of additional Axis II diagnoses (American Psychiatric Association, 2000) potentially influenced the course of treatment. Research indicates that the presence of antisocial personality traits is associated with poor outcomes among individuals with BPD (Clarkin, Hull, Yeomans, Kakuma, \& Cantor, 1994). There is some evidence that individuals with co-occurring personality disorders, and antisocial personality disorder in particular, have poorer outcomes in DBT (Salsman et al., 2008). Marie had no additional Axis II diagnoses whereas Dean was diagnosed with narcissistic personality disorder and antisocial features. Although Dean did not meet full criteria for antisocial personality disorder, the presence of these features coupled with the presence of additional co-occurring personality disorders could have adversely influenced Dean’s outcome as well.

\section{Therapeutic Alliance Factors}

As detailed previously, the alliance plays an important role in treatment in general and is especially important in the treatment of individuals (e.g., Horowitz et al., 1996; Spinhoven, Giesen-Bloo, van Dyck, Kooiman, \& Arntz, 2007). We selected these cases for study because of their different alliance trajectories. We will examine how these differences may have influenced outcome.

The alliance is built on three factors: agreement on therapeutic goals, agreement on therapeutic strategies, and the establishment of a trusting relationship. The different trajectories may reflect difficulties in one or more of these areas. One possibility is that Marie and Dean had a difference in their ability to identify and to agree upon goals. In Marie's case, she and her therapist identified a number of specific issues to address in treatment, including her suicidal behavior, alcohol use, anger, isolation, unemployment, and shame. In contrast, while Dean and his therapist identified treatment goals at treatment outset, Dean vacillated on his commitment to specific goals. For example, he initially committed to specific treatment goals including the elimination of self harm and help with getting a job. Whenever the therapist addressed these problems with him, he rejected help, contending that the problem was no longer an issue.

Different levels of commitment to goals may have influenced how Marie and Dean perceived treatment. In Marie's case, the therapist used strategies linked to her goals, including exposure to shame and other painful emotions. Marie and her therapist collaborated on the task of treatment; both agreed in the value of increasing her tolerance of shame as a means to reduce her anger and suicidal behaviors. Consequently, Marie readily participated in exposure exercises and the practice of skills. Dean's therapist also used exposure informally to reduce his phobic avoidance of shame related to discussing any problems. However, Dean may have perceived the therapist's use of informal exposure as pointlessly aversive since his commitment waivered.

Dean may have also experienced his therapist's use of validation strategies as aversive. For example, Dean frequently expressed anger towards the therapist in response to her efforts to validate him. He often reported that the therapist was not accurate in her efforts to understand. Dean may have been so threatened by being "seen" that he reacted with anger to mask underlying feelings of vulnerability and fear. Koerner (2009, March 17) notes that for many clients like Dean who have an extensive history of invalidation, validation needs to be provided 
Contrasting Clients in Dialectical Behavior Therapy for Borderline Personality Disorder:

"Marie" and "Dean," Two Cases with Different Alliance Trajectories \& Outcomes

L.A. Burckell \& S. McMain

Pragmatic Case Studies in Psychotherapy, http://pcsp.libraries.rutgers.edu

Volume 7, Module 2, Article 2, pp. 246-267, 06-05-11 [copyright by authors]

in measured doses. In other words, validation should be viewed as exposure and increased gradually over time. Consistent with this perspective, although Dean may have needed and craved validation, he may have been overwhelmed by it.

The therapist's attention to treatment-interfering behaviors may have impacted the alliance. During the precommitment phase of DBT, therapists discuss the purpose of analyzing any behaviors that interfere with treatment engagement, including missing sessions, urges to drop out of treatment, failure to complete homework assignments, and relationship difficulties. Although focusing on therapy-interfering behaviors is adherent to DBT, repeatedly focusing on these behaviors in the absence of shared goals or a strong bond may contribute to further deterioration of a poor alliance. As Linehan (1993) notes, a strong alliance allows the therapist to push more for change. The relationship can be used as a contingency to reinforce functional behaviors and to extinguish dysfunctional behaviors. Dean's therapist may have pushed for change without having developed a strong relationship. Consistent with this view, Dean may not have cared enough about the therapist, their relationship, or therapy to be motivated to engage in treatment and to do the things necessary to improve the relationship, including stopping his angry attacks towards the therapist.

The quality of the relationship likely contributed to the differential outcomes. Specifically, a key aspect of the alliance is the nature of the bond, or the degree to which clients and therapists feel that their relationship is build on trust, understanding, and acceptance. There are several indicators to suggest that there were significant differences the bond in the two therapies. Although both Marie and Dean were hostile to their therapists at the outset of therapy, the therapists reacted differently to these attacks. Marie's therapist felt warmly towards Marie. She was able to see her anxiety underneath the anger and attacks. As a result, Marie's therapist was able to maintain warmth and validation throughout treatment. Marie's therapist felt as though she understood Marie and cared for her.

Similarly, while Dean's therapist recognized that Dean's anger and attacks were secondary to underlying shame, she also reported that she struggled with feeling compassionate in the face of Dean's frequent the attacks towards her. In fact the therapist described feeling "wounded" by Dean, which may have contributed to her problems maintaining a dialectical stance and being able to genuinely validate Dean. While Dean's therapist attempted to understand Dean, she described that she felt that something missing in her understanding. For example, when Dean's therapist validated Dean, her validation was met with by hostility, and a sense of connection was diminished. These repeated unsuccessful attempts to repair the relationship left the therapist feeling demoralized and hopeless that anything would work. Ultimately, both she and Dean remained at an impasse for most of treatment, both unable to extract themselves from polarized positions. Unsurprisingly, Dean's ratings of the alliance remained low throughout treatment.

\section{$\underline{\text { Relationship between the DBT Team and Therapist }}$}

The therapist's relationship with the treatment team can influence the course of treatment. The key function of the consultation team is to motivate the therapist and to increase the 
"Marie" and "Dean," Two Cases with Different Alliance Trajectories \& Outcomes

L.A. Burckell \& S. McMain

Pragmatic Case Studies in Psychotherapy, http://pcsp.libraries.rutgers.edu

Volume 7, Module 2, Article 2, pp. 246-267, 06-05-11 [copyright by authors]

therapist's adherence to DBT (Linehan, 1993). The challenges Dean's therapist had in maintaining her motivation to help Dean suggest that the DBT consultation team may have failed in supporting the therapist. There are several reasons that the team may not have provided sufficient support to help the therapist. First, Dean's therapist was often unsure about what she needed from the team. While the role of the team is to help therapists to clarify their needs, in this case, they had difficulty helping the therapist clarify what she needed. Second, the team may have been imbalanced themselves and remained overly focused on change. The consultation team helps the therapist identify what's missing in the therapist's conceptualization and approach. Dean's therapist was working to make the relationship work and was out of balance by focusing on change. Similarly the team was overly focused on change strategies and searching for solutions without sufficiently offering validation to the therapist. Both Dean's therapist and the team may have been so focused on solving problems they may have overly emphasized problem-solving strategies at the expense of validation and understanding. Additionally, problem-solving may have functioned to reduce the anxiety that Dean's therapist and the team felt about the case in the short-term; however, in the long-term, this approach maintained the pattern. Third, this focus on change impacted the team's ability to validate Dean's therapist. Specifically, when the therapist vocalized lack of progress with Dean, the group leaders and other team members would highlight Dean's progress outside of individual therapy. Dean's therapist viewed these attempts to promote hope as invalidating; she felt that these comments dismissed her difficulties.

A number of obstacles may have contributed to the team being off balance and failing to recognize that they were stuck. The emphasis on problem-solving within the team was influenced by the research context; there was an additional pressure to retain clients to achieve an adequate sample size. Furthermore, Dean's therapist was so hurt by Dean's attacks that it was difficult for her to maintain a validating and dialectical stance, or to accept feedback nondefensively. Her own dysregulation was further compounded by the invalidation she felt about the team's unsuccessful attempts to validate her. Finally, Dean's therapist was a skilled therapist. Ultimately, all of these factors may have contributed to the differences in the alliance trajectories and outcome.

\section{Summary}

We believe that the comparison of the cases of Marie and Dean highlights potential factors related to treatment outcome in DBT. These cases suggest how critical building a strong alliance is in DBT and how both the individual therapist and consultation team contribute to this process. Consistent with some of our other findings (Burckell \& McMain, 2008), these clinical cases illustrate that a poor initial alliance is not necessarily predictive of outcome for individuals with BPD. However, these cases suggest that developing an alliance at some point in therapy is importantly beneficial. Future research can investigate how early this is needed and what strategies are most beneficial to developing a strong alliance.

Also, comparison of these cases points to the potential role that additional personality diagnoses may play in treatment outcome. In Dean's case, the additional diagnosis of narcissistic personality disorder and antisocial features may have contributed to his treatment compliance 
issues and to his difficulties forming a relationship with his therapist. Future research could help to uncover strategies that might be particularly useful to engage clients like Dean.

Finally, comparison of these cases suggests how important a role the DBT consultation team plays in treatment. While the consultation team is a required element of DBT (Linehan, 1993a), there has been no systematic research on its role in its relationship to outcome. Future research needs to examine how the individual therapist and consultation team can work together to promote better clinical outcomes. 
"Marie" and "Dean," Two Cases with Different Alliance Trajectories \& Outcomes

L.A. Burckell \& S. McMain

Pragmatic Case Studies in Psychotherapy, http://pcsp.libraries.rutgers.edu

Volume 7, Module 2, Article 2, pp. 246-267, 06-05-11 [copyright by authors]

\section{REFERENCES}

American Psychiatric Association (2000). Diagnostic and statistical manual of mental disorders, fourth edition (DSM-IV-TR). (4th ed.) Washington, DC: American Psychiatric Association Press.

Aviram, R. B., Brodsky, B. S., \& Stanley, B. (2006). Borderline personality disorder, stigma, and treatment implications. Harvard Review of Psychiatry, 14, 249 - 256.

Beck, A.T., Steer, R. A., \& Brown, G. K. (1996). Manual for Beck Depression Inventory II. San Antonio, TX: Psychological Corporation.

Bender, D. S., Dolan, R. T., Skodol, A. E., Sanislow, C. A., Dyck, I.R., \& McGlashan, T. H. (2001). Treatment utilization by patients with personality disorders. American Journal of Psychiatry, 158, 295-302.

Burckell, L. A., \& McMain, S. (2008, November). The Relationship of the Therapeutic Alliance to Outcome and Retention in the Treatment of Borderline Personality Disorder. Presented at the annual meeting of the Association of Cognitive and Behavioral Therapies in Orlando, Florida.

Clarkin, J. F., Hull, J., Yeomans, F., Kakuma, T., \& Cantor, J. (1994). Antisocial traits as modifiers of treatment response in borderline inpatients. Journal of Psychotherapy Practice and Research, 3, 307-312.

Crowell, S. E., Beauchaine, T. P., \& Linehan, M. (2009). A biosocial developmental model of borderline personality: Elaborating and extending Linehan’s theory. Psychological Bulletin, 135, 495-510.

Derogatis, L. R. (1993). SCL-90-R administration, scoring and procedure manual. Baltimore: Clinical Psychiatric Research.

First, M. B., Spitzer, R. L., Gibbon, M., and Williams, J. B. W. (1995). Structured Clinical Interview for Axis I DSM-IV Disorders - Patient Edition (SCID-I/P). New York: Biometrics Research Department, NY State Psychiatric Institute.

Horowitz, L. M., Rosenberg, S. E., Baer, B. A., Ureño, G., \& Villaseñor, V. S. (1988). The Inventory of Interpersonal Problems: Psychometric properties and clinical applications. Journal of Consulting and Clinical Psychology, 56, 885-895.

Horowitz, L., Gabbard, G. O., Allen, J. G., Frieswyk, S. H., Colson, D. B., Newsom, G. E., \& Coyne, L. (1996). Borderline Personality Disorder: Tailoring the Psychotherapy to the Patient. Washington, D.C.: American Psychiatric Press, Inc.

Koerner, K. (2009, March 17). Resources \& Timeline for Validation Sprint (Ready, set...). Personal communication.

Koerner, K., \& Linehan, M. M. (1996). Case formulation in Dialectical Behavior Therapy for borderline personality disorder. In T. Eells (Ed.) Handbook of Psychotherapy Case Formulation. (pp. 340-367). New York: Guilford.

Koons, C. R., Robins, C. J., Tweed, J. L., Lynch, T. R., Gonzalez, A. M., Morse, J. Q., Bishop, G. K., Butterfield, M. I., \& Bastian, L. A. (2001). Efficacy of dialectical behavior therapy in women veterans with borderline personality disorder. Behavior Therapy, 32, 371-390.

Linehan, M. M. (1993). Cognitive behavioral therapy for borderline personality disorder. New York: Guilford. 
"Marie" and "Dean," Two Cases with Different Alliance Trajectories \& Outcomes

L.A. Burckell \& S. McMain

Pragmatic Case Studies in Psychotherapy, http://pcsp.libraries.rutgers.edu

Volume 7, Module 2, Article 2, pp. 246-267, 06-05-11 [copyright by authors]

Linehan, M. M. (1993b). Global Rating Scale. Unpublished Work.

Linehan, M. M. \& Comtois, K. (1996a). Lifetime Parasuicide History. University of Washington, Seattle, WA, Unpublished work.

Linehan, M. M., Comtois, K. A., Brown, M. Z., Heard, H. L., \& Wagner, A. (2006). Suicide Attempt Self-Injury Interview (SASII): Development, reliability, and validity of a scale to assess suicide attempts and intentional self-injury. Psychological Assessment, 18, 303312.

Linehan, M. M., Wagner, A. W., \& Cox, G. (1993b).Parasuicide history interview: Comprehensive assessment of parasuicidal behavior. University of Washington, Seattle: Unpublished manuscript; 1983.

Loranger, A.W. (1995). International Personality Disorder Examination (IPDE) Manual. White Plains, NY: Cornell Medical Center.

McMain, S. F., Links, P. S. Gnam, W. H.., Guimond, T., Cardish, R. J., Korman, L., \& Streiner, D. L. (2009). A randomized trial of Dialectical Behavior Therapy versus General Psychiatric Management for Borderline Personality Disorder. American Journal Of Psychiatry, 166, 1365-1374.

Nafisi, N, \& Stanley, B. (2007). Developing and maintaining the therapeutic alliance with selfinjuring patients. Journal of Clinical Psychology, 63, 1069-1079.

Norcross, J. C., Krebs, P. M. \& Prochaska, J. O. (2011). Stages of change. Journal of Clinical Psychology: In Session 67, 143-154

Salsman, N. L., Harned, M. S., Secrist, C. D., Comtois, K. D., \& Linehan, M. M. (2008, August). Client Predictors of Treatment Response in Dialectical Behavior Therapy across Multiple RCTs. Presented at the annual meeting of the American Psychological Association in Boston, Massachusetts.

Skodol, A. E., Buckley, P., Charles, E. (1983). Is there a characteristic pattern to the treatment history of clinic outpatients with borderline personality disorder? Journal of Nervous and Mental Disease, 171, 405-410.

Spielberger C. D. (1988). Manual for the State-Trait Anger Expression Inventory. Odessa, FL: Psychological Assessment Resources, Inc.

Spinhoven, P., Gisen-Bloo, J., van Dyck, R., Kooiman, K., \& Arntz, A. (2007). The therapeutic alliance in Schema-Focused Therapy and Tranference-Focused Psychotherapy for borderline personality disorder. Journal of Consulting and Clinical Psychology, 75, 104115.

Swales, M. A., \& Heard, H. L. (2007).The therapy relationship in dialectical behavior therapy. In (eds.) Gilbert, P., \& Leahy, R. L. The Therapeutic Relationship in the Cognitive Behavioral Psychotherapies. London: Routledge.

Zanarini, M. C., Frankenburg, F.R., Hennen, J., \& Silk, K.R. (2004).Mental health service utilization by borderline personality disorder patients and Axis II comparison subjects followed prospectively for 6 years. Journal of Clinical Psychiatry. 65, 28-36.

Zanarini, M. C., Vujanovic, A. A., Parachini, E. A., Boulanger, J. L., Frankenburg, F. R., \& Hennen, J. (2003). Zanarini Rating Scale for Borderline Personality Disorder (ZANBPD): a continuous measure of DSM-IV borderline psychopathology. Journal of Personality Disorders, 17, 233-242. 
"Marie" and "Dean," Two Cases with Different Alliance Trajectories \& Outcomes

L.A. Burckell \& S. McMain

Pragmatic Case Studies in Psychotherapy, http://pcsp.libraries.rutgers.edu

Volume 7, Module 2, Article 2, pp. 246-267, 06-05-11 [copyright by authors]

Table 1. Outcome Measures at Baseline, During Treatment, and through 18-Month Follow Up ${ }^{a}$

Primary Outcomes
\begin{tabular}{|c|c|c|}
\multicolumn{2}{l}{ Marie } & Dean \\
\hline Number of Suicidal and Self-Injurious Behaviors ${ }^{, b, c}$ & & \\
\hline Baseline - Pretreatment Assessment & 9 & 26 \\
\hline Treatment - 4 months & 2 & 2 \\
\hline Treatment - 8 months & 0 & 0 \\
\hline Treatment - 12 months & 0 & 0 \\
\hline Follow Up - 6 Months & 0 & 16 \\
\hline Follow Up - 12 Months & 0 & 8 \\
\hline Follow Up - 18 Months & 1 & 0 \\
\hline
\end{tabular}

\begin{tabular}{|c|c|c|}
\hline Number of ER Visits Due to Suicidal Behavior $^{b, c}$ & & \\
\hline Baseline - Pretreatment Assessment & 6 & 0 \\
\hline Treatment - 4 months & 0 & 0 \\
\hline Treatment - 8 months & 0 & 0 \\
\hline Treatment - 12 months & 0 & 0 \\
\hline Follow Up - 6 Months & 0 & 0 \\
\hline Follow Up - 12 Months & 0 & 1 \\
\hline Follow-Up - 18 Months & & \\
\hline
\end{tabular}

\begin{tabular}{|c|c|c|}
\hline Number of Psychiatric FloorAadmissions ${ }^{b, c}$ & & \\
\hline Baseline - Pretreatment Assessment & 7 & 0 \\
\hline Treatment - 4 months & 0 & 0 \\
\hline Treatment - 8 months & 0 & 0 \\
\hline Treatment - 12 months & 0 & 0 \\
\hline Follow Up - 6 Months & 0 & 0 \\
\hline Follow Up - 12 Months & 0 & 0 \\
\hline Follow Up - 18 Months & 1 & 0 \\
\hline
\end{tabular}

\begin{tabular}{|c|c|c|}
\hline Number of Psychiatric Floor Days ${ }^{b, c}$ & & \\
\hline Baseline - Pretreatment Assessment & 8 & 0 \\
\hline Treatment - 4 months & 0 & 0 \\
\hline Treatment - 8 months & 0 & 0 \\
\hline Treatment - 12 months & 0 & 0 \\
\hline Follow Up - 6 Months & 0 & 0 \\
\hline Follow Up - 12 Months & 0 & 0 \\
\hline Follow Up - 18 Months & 1 & 0 \\
\hline
\end{tabular}


"Marie" and "Dean," Two Cases with Different Alliance Trajectories \& Outcomes

L.A. Burckell \& S. McMain

Pragmatic Case Studies in Psychotherapy, http://pcsp.libraries.rutgers.edu

Volume 7, Module 2, Article 2, pp. 246-267, 06-05-11 [copyright by authors]

Table 1 (continued)

Secondary Outcomes

Marie Dean

\begin{tabular}{|c|c|c|}
\hline depression (Beck Depression Inventory $^{\mathrm{d}}$ ) & & \\
\hline Baseline - Pretreatment Assessment & & 27 \\
\hline Treatment - 4 months & 21 & 38 \\
\hline Treatment - 8 months & & \\
\hline Treatment - 12 months & 25 & 59 \\
\hline Follow Up - 6 Months & 15 & \\
\hline Follow Up - 12 Months & & 24 \\
\hline Follow Up - 18 Months & & \\
\hline
\end{tabular}

\begin{tabular}{|c|c|c|}
\hline anger (STAXI Anger-Out ${ }^{e}$ ) & & \\
\hline Baseline - Pretreatment Assessment & 10 & 13 \\
\hline Treatment - 4 Months & 12 & 13 \\
\hline \multicolumn{3}{|l|}{ Treatment - 8 Months } \\
\hline Treatment - 12 Months & 14 & 22 \\
\hline Follow Up - 6 Months & 11 & \\
\hline \multicolumn{3}{|l|}{ Follow Up - 12 Months } \\
\hline Follow Up, 18 Months & 17 & 14 \\
\hline \multicolumn{3}{|l|}{ general distress (SCL-90 Global Severity Index ${ }^{f}$ ) } \\
\hline Baseline - Pretreatment Assessment & 1.72 & 0.13 \\
\hline Treatment -4 Months & 0.89 & 1.19 \\
\hline \multicolumn{3}{|l|}{ Treatment - 8 Months } \\
\hline Treatment - 12 Months & 1.01 & 2.71 \\
\hline Follow Up - 6 Months & 1.06 & \\
\hline \multicolumn{3}{|l|}{ Follow Up - 12 Months } \\
\hline Follow Up - 18 Months & 2.71 & 1.90 \\
\hline \multicolumn{3}{|l|}{$\begin{array}{l}\text { interpersonal problems (Inventory of Interpersonal } \\
\text { Problems }{ }^{g} \text { ) }\end{array}$} \\
\hline Baseline - Pretreatment Assessment & 109 & 57 \\
\hline Treatment - 4 Months & 107 & 81 \\
\hline Treatment - 8 Months & 129 & \\
\hline Treatment - 12 Months & 130 & 146 \\
\hline Follow Up - 6 Months & 118 & \\
\hline \multicolumn{3}{|l|}{ Follow Up - 12 Months } \\
\hline Follow Up - 18 Months & 154 & 111 \\
\hline \multicolumn{3}{|l|}{ BPD symptoms (ZAN-BPD $\left.{ }^{h}\right)$} \\
\hline Baseline - Pretreatment Assessment & 17 & 15 \\
\hline Treatment - 4 Months & 10 & 8 \\
\hline Treatment - 8 Months & 9 & 12 \\
\hline Treatment - 12 Months & 5 & 3 \\
\hline Follow Up - 6 Months & 1 & 7 \\
\hline Follow Up - 12 Months & 5 & 12 \\
\hline Follow Up - 18 Months & 11 & 8 \\
\hline
\end{tabular}

${ }^{a}$ Empty cells reflect missing data; ${ }^{b}$ L-SASI (Linehan \& Comtois, 1996); ${ }^{c}$ SASII (Linehan, Comtois, Brown, Heard, \& Wagner, 2006; Linehan, Wagner, \& Cox, 1993); ${ }^{\mathrm{d}}$ Beck et al., 1996; ${ }^{\mathrm{e}}$ Spielberger,1988; ${ }^{\dagger}$ Derogatis, 1993; ${ }^{\text {}}$ Horowitz, 2004; ${ }^{\text {h }}$ Zanarini et al., 2003 
Contrasting Clients in Dialectical Behavior Therapy for Borderline Personality Disorder:

"Marie" and "Dean," Two Cases with Different Alliance Trajectories \& Outcomes

L.A. Burckell \& S. McMain

Pragmatic Case Studies in Psychotherapy, http://pcsp.libraries.rutgers.edu

Volume 7, Module 2, Article 2, pp. 246-267, 06-05-11 [copyright by authors]

Figure 1. Marie and Her Therapist's Ratings of the Alliance Across Treatment

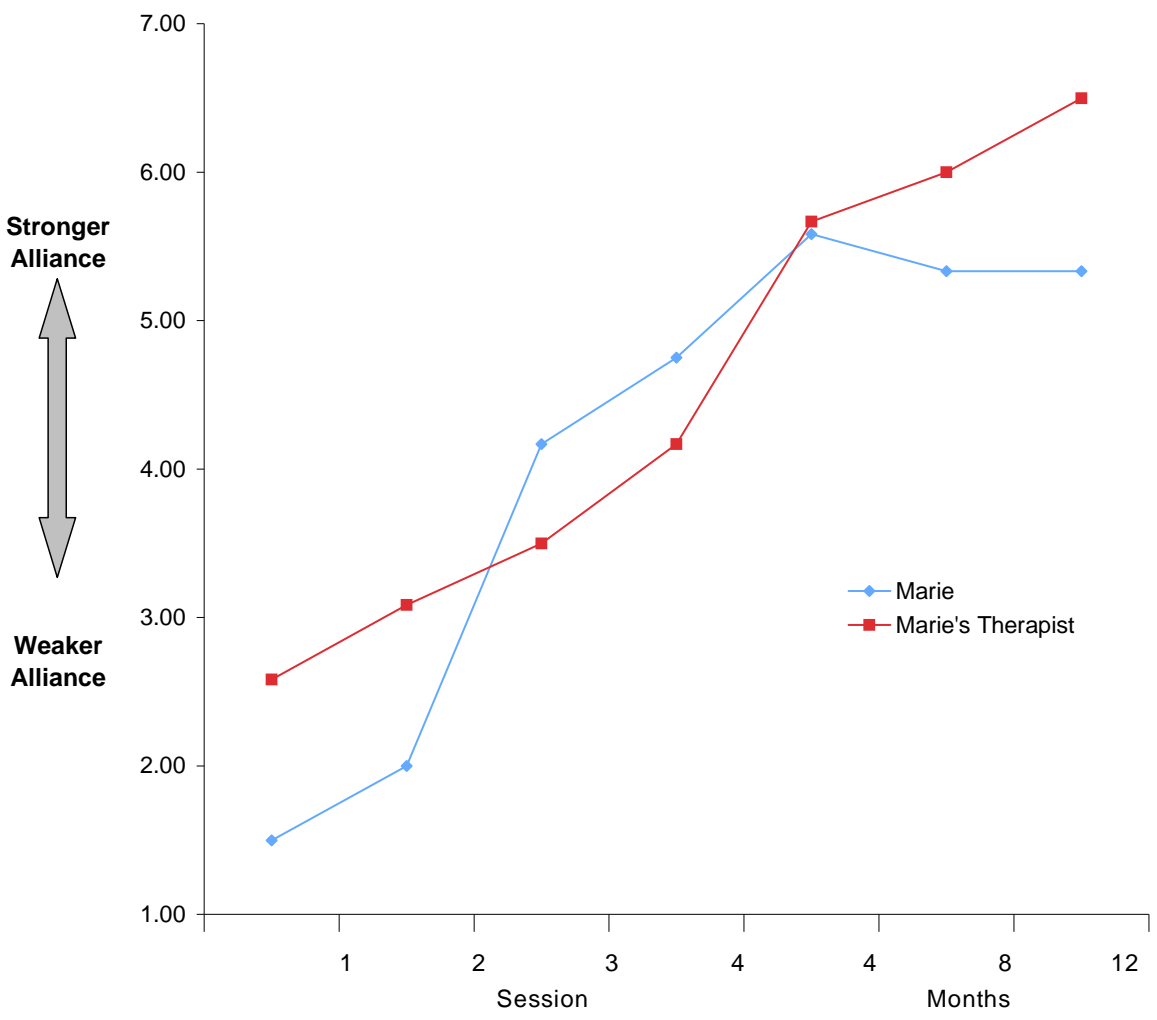


Contrasting Clients in Dialectical Behavior Therapy for Borderline Personality Disorder:

"Marie" and "Dean," Two Cases with Different Alliance Trajectories \& Outcomes

L.A. Burckell \& S. McMain

Pragmatic Case Studies in Psychotherapy, http://pcsp.libraries.rutgers.edu

Volume 7, Module 2, Article 2, pp. 246-267, 06-05-11 [copyright by authors]

Figure 2. Dean and His Therapist's Ratings of the Alliance Across Treatment

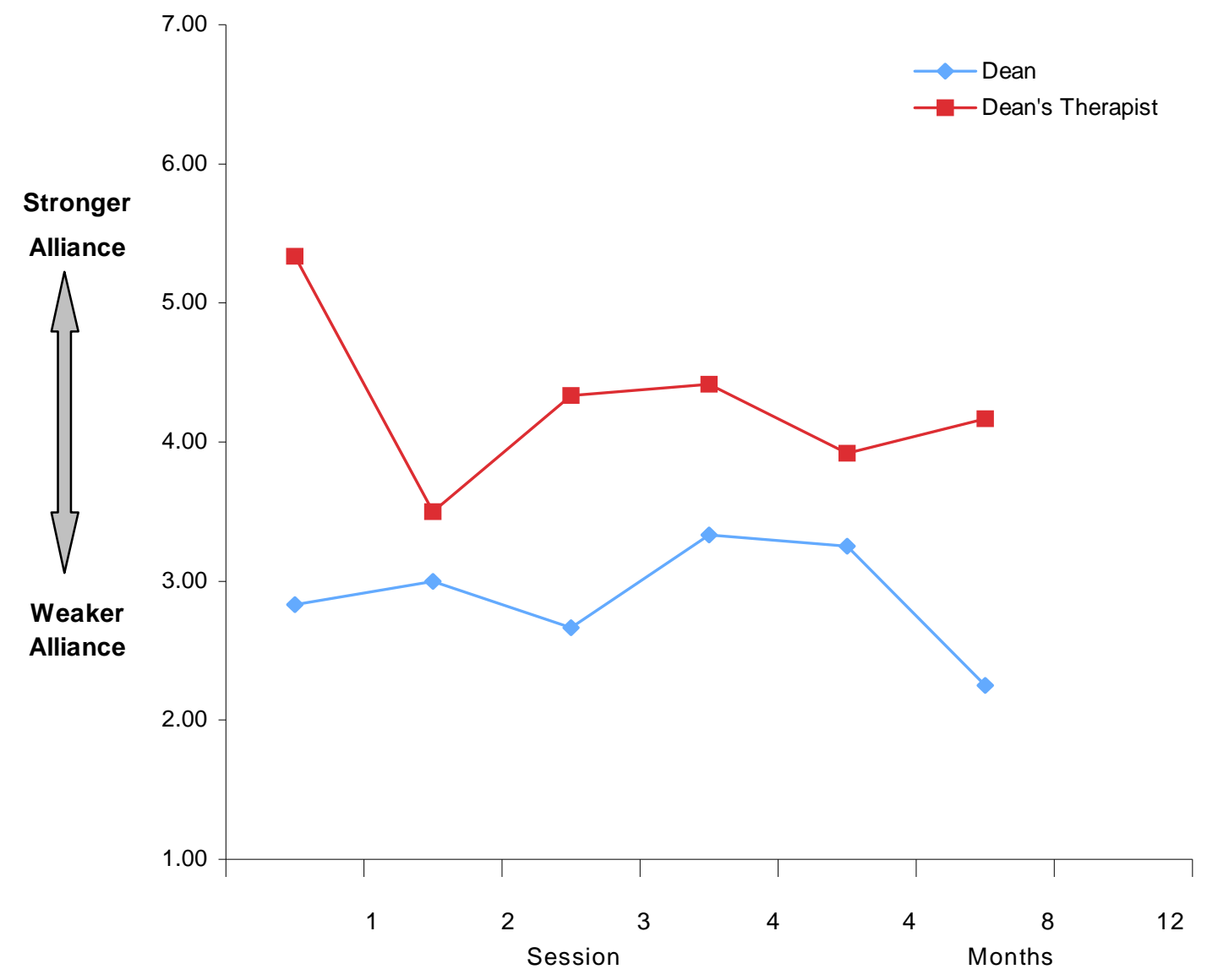

